\title{
Estimating diet composition from scat analysis in otariid seals (Otariidae): is it reliable?
}

\author{
T. Dellinger and F. Trillmich \\ Max-Planck Institut für Verhaltensphysiologie, Abteilung Wickler, D-8131 Seewiesen, Federal Republic of Germany \\ Received September 25, 1987
}

\begin{abstract}
Dellinger, T., and Trillmich, F. 1988. Estimating diet composition from scat analysis in otariid seals (Otariidae): is it reliable? Can. J. Zool. 66: $1865-1870$.

Analysis of teleost sagittal otoliths contained in scats has been widely used to determine the diet of seals. This method is based on the assumption that relative frequencies of otoliths in scats faithfully reflect those of fish in the diet. This assumption has rarely been tested experimentally. We compared the ratios of herring (Clupea harengus) to sprat (Sprattus sprattus) otoliths in faeces (output) of captive California sea lions (Zalophus californianus) and South American fur seals (Arctocephalus australis) with the ratios at feeding (input). Sea lions and fur seals showed no consistent differences in recovery rates and partial digestion of otoliths. Output ratios deviated only slightly from input ratios, the smaller sprat otoliths being underrepresented in the output by $8 \%$. Only about $40 \%$ of the otoliths fed to the seals were found in the scats. For both species partial digestion of otoliths led to a $16 \%$ underestimation of fish length and a $35 \%$ underestimation of fish mass.
\end{abstract}

Dellinger, T., et Trullmich, F. 1988. Estimating diet composition from scat analysis in otariid seals (Otariidae): is it reliable? Can. J. Zool. $66: 1865-1870$.

L'analyse des otolithes de téléostéens contenus dans les fèces est une méthode très répandue de détermination du régime alimentaire des phoques. Cette méthode suppose que les fréquences relatives d'otolithes dans les fèces reflètent fidèlement les fréquences relatives des poissons dans le régime. Cette prémisse n'a pratiquement jamais fait l'objet de vérifications expérimentales. Nous avons mesuré la proportion d'otolithes de harengs (Clupea harengus) et celle d'otolithes de sprats (Sprattus sprattus) dans les fèces (sortie) de Lions de mer californiens, Zalophus californianus, et d'Otaries à fourrure sudaméricaines, Arctocephalus australis, gardés en captivité, et comparé ces mesures aux proportions d'otolithes ingérés (entrée). Il n'y avait pas de différence constante entre lions de mer et otaries et les taux de récupération et de digestion partielle d'otolithes étaient les mêmes chez les deux espèces. Les proportions à la sortie différaient seulement un peu des proportions à l'entrée et les otolithes des sprats, plus petits, étaient sous-représentés de $8 \%$ à la sortie. Seulement $40 \%$ environ des otolithes ingérés ont été retrouvés à la sortie. La digestion partielle des otolithes chez les deux espèces entraîne une sous-estimation de la longueur des poissons consommés, de l'ordre de $16 \%$, et de la masse des poissons consommés, de l'ordre de $35 \%$.

[Traduit par la revue]

\section{Introduction}

Analysis of teleost sagittal otoliths contained in scats is a frequently employed method for assessing the composition of pinniped food. Otoliths found in scats can often be identified to species, and fish mass and length can be estimated from otolith length. However, otoliths are mainly composed of aragonite (Degens et al. 1969) and are therefore liable to be dissolved in the acid stomach juices of seals. Although total or partial digestion of otoliths has been recognized as a serious problem by previous authors (Prime 1979; North et al. 1983; DaSilva and Neilson 1985; Prime and Hammond 1987), few experimental studies have been conducted. These studies have shown that otoliths can decrease in length during passage through the intestinal tract, that recovery of ingested otoliths can be very low (Hawes 1983; DaSilva and Neilson 1985), that the probability of an otolith being digested depends on the fish species but appears to be a random event for otoliths of a given species in a meal (Murie and Lavigne 1985), and that otoliths of different fish species may not appear in scats in the same ratios in which they were eaten (Hawes 1983). While estimates of total biomass intake derived from otoliths in scats therefore appear unreliable (unless complex corrections for total and partial digestion are made), it is not so clear whether the relative frequencies of otoliths in scats provide a reliable estimate of the relative number of fish ingested.

The primary objective of this study was to provide a basis for the interpretation of otolith numbers counted in scats in field collections. We report feeding experiments on captive individuals of two species of otariid seals, the California sea lion (Zalophus californianus) and South American fur seal (Arctocephalus australis). These animals were fed known diets of herring (Clupea harengus) and sprat (Sprattus sprat$t u s$ ). We determined recovery rates of herring and sprat otoliths, and changes in otolith length, and looked for differences in otolith digestion between the two seal species. Particular emphasis was placed on the comparison of known relative number of fish at feeding to estimated ratios in the diet as derived from otolith counts in scats.

\section{Animals and methods}

For the feeding experiments we used two adult female sea lions of unknown age weighing about $120 \mathrm{~kg}$, two adult female South American fur seals of unknown age weighing about $40-50 \mathrm{~kg}$, and one 5.5-year-old subadult male South American fur seal weighing about $60 \mathrm{~kg}$. The animals were kept in a freshwater pool at the Munich Zoo "Hellabrunn," Federal Republic of Germany. Before the experiments they were fed a diet of freshly thawed herring and (or) mackerel (Scomber scombrus).

During the experiments each seal was kept isolated in a closed, tiled room with an area of about $12 \mathrm{~m}^{2}$ and one window in the roof. Because four of these rooms were available, experiments on two animals of each species were run concurrently. The seals were fed the experimental meal almost simultaneously. Five series of experiments were run, the first consisting of one sea lion and two fur seals (Table 1). To reduce the effect of confinement, the animals were allowed some time together every day in a common larger room, but only under constant surveillance. As the seals had no opportunity to enter a pool they were hosed down with water several times a day. Both movement in the common room and wetting enhanced the seals' probability of defecation. 
TABLE 1. Conditions of the five sets of experiments

\begin{tabular}{ccccc}
\hline \hline $\begin{array}{c}\text { Series } \\
\text { No. }\end{array}$ & $\begin{array}{c}\text { Animal } \\
\text { No. }\end{array}$ & $\begin{array}{c}\text { Period fed decapitated } \\
\text { fish before experimental } \\
\text { meal (days) }\end{array}$ & $\begin{array}{c}\text { Time glass beads } \\
\text { were fed before } \\
\text { experimental meal } \\
\text { (h) }\end{array}$ & $\begin{array}{c}\text { Max. time in } \\
\text { captivity after } \\
\text { experimental meal } \\
\text { (h) }\end{array}$ \\
\hline 1 & $1,4,6$ & 3 & - & 91 \\
2 & $1,2,4,6$ & 2 & - & 94 \\
3 & $1,2,3,4$ & 7 & $171,123,75,26$ & 68 \\
4 & $1,2,3,4$ & 8 & $48,24,0$ & 104 \\
5 & $1,2,3,4$ & 7 & $48,25,22,0$ & 69 \\
\hline
\end{tabular}

Note: Animals 1 and 2 are sea lions, animals 3,4, and 6 are fur seals. A different color of glass beads was given at each time when glass beads were fed several times before the experimental meal. Duration of captivity gives the time after which the last animal of a set of experiments was released.

For 2-8 days before each experiment the animals were fed decapitated fish to ensure that no otoliths remained in their digestive tracts (Table 1). The efficiency of this procedure was insured by collecting and scrutinizing faeces before the experimental feeding. The experimental feeding at the beginning of each series consisted of varying amounts and combinations of herring and sprat with heads. Herring had a mean standard length of $20.9 \mathrm{~cm}$ and weighed about $190 \mathrm{~g}$, sprat had a mean length of $12.1 \mathrm{~cm}$ and weighed about $18 \mathrm{~g}$. The seals were hand-fed individually and the time of feeding and mass, standard length, and number of fishes fed per animal were recorded. Each seal received about $2.5-3.5 \mathrm{~kg}$ of fish at the experimental feeding. When high numbers of herring had to be fed to the seals, some herring were cut in half obliquely from the base of the skull to the anus and only the head parts were given. Other herring had their abdominal cavities stuffed with herring heads. Following experimental feeding the animals again received decapitated fish only, twice daily at $11: 30$ and 14:30, amounting to $3-4 \mathrm{~kg} \mathrm{day}^{-1}$. An experiment was terminated either when two successive scats contained no otoliths, or when the duration of the experiment exceeded 3-4 days. The shortest experiment lasted $68 \mathrm{~h}$ from the time of experimental feeding (Table 1).

During some experiments glass beads were used as meal marking devices, with different colors marking specific feeding times. The glass beads were contained in gelatine capsules, each holding 30 beads. Three capsules were inserted into the abdominal cavity of one or more fishes before feeding. Beads were fed at various times before and at the time of the experimental feeding (Table 1). When fed at experimental feeding they also served as a control for otolith recovery.

As far as possible all faecal material was collected and defecation time noted. Sometimes an animal squashed a scat with its body. These scats were also gathered as completely as possible. Visual inspection indicated that more than $90 \%$ of all scats were thus recovered. Defecation during the night was rare. Animals were not observed during the night and for the few scats found in the morning the time of defecation was assumed to be 09:00.

Otoliths were recovered by immersing scats in water mixed with household detergent to help emulsify the soft constituents of the scats. The scats were then strained through three nested sieves with 2.0-, $1.0-$, and $0.5-\mathrm{mm}$ mesh sizes. The otoliths were collected from the sieves with a pair of forceps, briefly washed in $98 \%$ isopropyl alcohol, air-dried, and stored dry. Otoliths were then identified as belonging to sprat or herring and their lengths were measured to the nearest $0.1 \mathrm{~mm}$ from the rostrum to the postrostrum using a stereomicroscope (Wild-M7S) at about 30 times magnification.

Sagittal otoliths were removed from 22 fresh herring and 22 fresh sprats and their lengths regressed on standard fish lengths and fish body masses. To compare lengths of otoliths before and after passage through the digestive tracts of the experimental animals, expected otolith lengths were estimated from measured standard lengths of fish before feeding. From the measured lengths of otoliths in scats, estimated lengths and body masses of fresh fish in the diet were calculated from regressions.

\section{Results}

\section{Percent otolith recovery}

A mean of $38.5 \pm 29.5 \%$ of otoliths fed during all experiments were recovered in the scats. From fur seal scats, $42.0 \pm 23.8 \%$ of all sprat otoliths were recovered $(n=8$ experiments; 285 of 564 otoliths) and $49.4 \pm 26.7 \%$ of all herring otoliths were recovered ( $n=10 ; 309$ of 590 otoliths). From sea lion scats, we recovered $26.4 \pm 33.8 \%$ of ingested sprat otoliths $(n=8 ; 141$ of 570$)$ and $34.2 \pm 32.7 \%$ of ingested herring otoliths $(n=9 ; 199$ of 538). The lower recovery from sea lion scats resulted from very low values for one of the sea lions $(3.0 \pm 1.9 \%$ in four experiments), while recovery for the other sea lion was similar to that of the fur seals $(55.3 \pm 26.0 \%$ in five experiments $)$. Otolith recovery was not significantly different between the two species (Mann-Whitney $U$-test; $n_{1}=17, n_{2}=18$, ns).

For both species together, more of the herring than sprat otoliths were recovered (Wilcoxon signed-ranks test, $n=16$, $p<0.05$ ) indicating that the number of the smaller sprats in the diet would be underestimated from scat analysis. However, results of the test were not significant for each seal species separately.

\section{Percent glass beads recovered}

As glass beads are indigestible they can serve to assess the proportion of otoliths defecated but not recovered. For each seal species glass beads were fed simultaneously with the experimental feeding (four times). The cumulative curve of glass bead recovery reached saturation after about $30 \mathrm{~h}$ with little further recovery up to $80 \mathrm{~h}$ after the experimental feeding (Fig. 1A). For otoliths saturation was reached after $20-50 \mathrm{~h}$ (Fig. 1B) indicating that further defecation of glass beads or otoliths was unlikely after the end of the experiments. A mean of $74.0 \pm 37.7 \%$ ( $n=8$ experiments) of glass beads fed with the experimental feedings were recovered in scats. No difference was found between the two seal species (MannWhitney $U$-test: $n_{1}=4, n_{2}=4$, ns).

Only $5.8 \%$ ( 68 of 1170 ) of beads fed $20-25 \mathrm{~h}$ before the experimental feeding were found in scats collected after the experimental feeding. Of beads fed $>25 \mathrm{~h}$ before the experimental feeding only $0.1 \%$ ( 2 of 1860 ) were recovered during the experiments.

\section{Passage half-times}

The time between the experimental feeding and recovery of $50 \%$ of all otoliths recovered is here called the passage halftime. It provides an estimate of the average time an otolith was exposed to digestive fluids. 

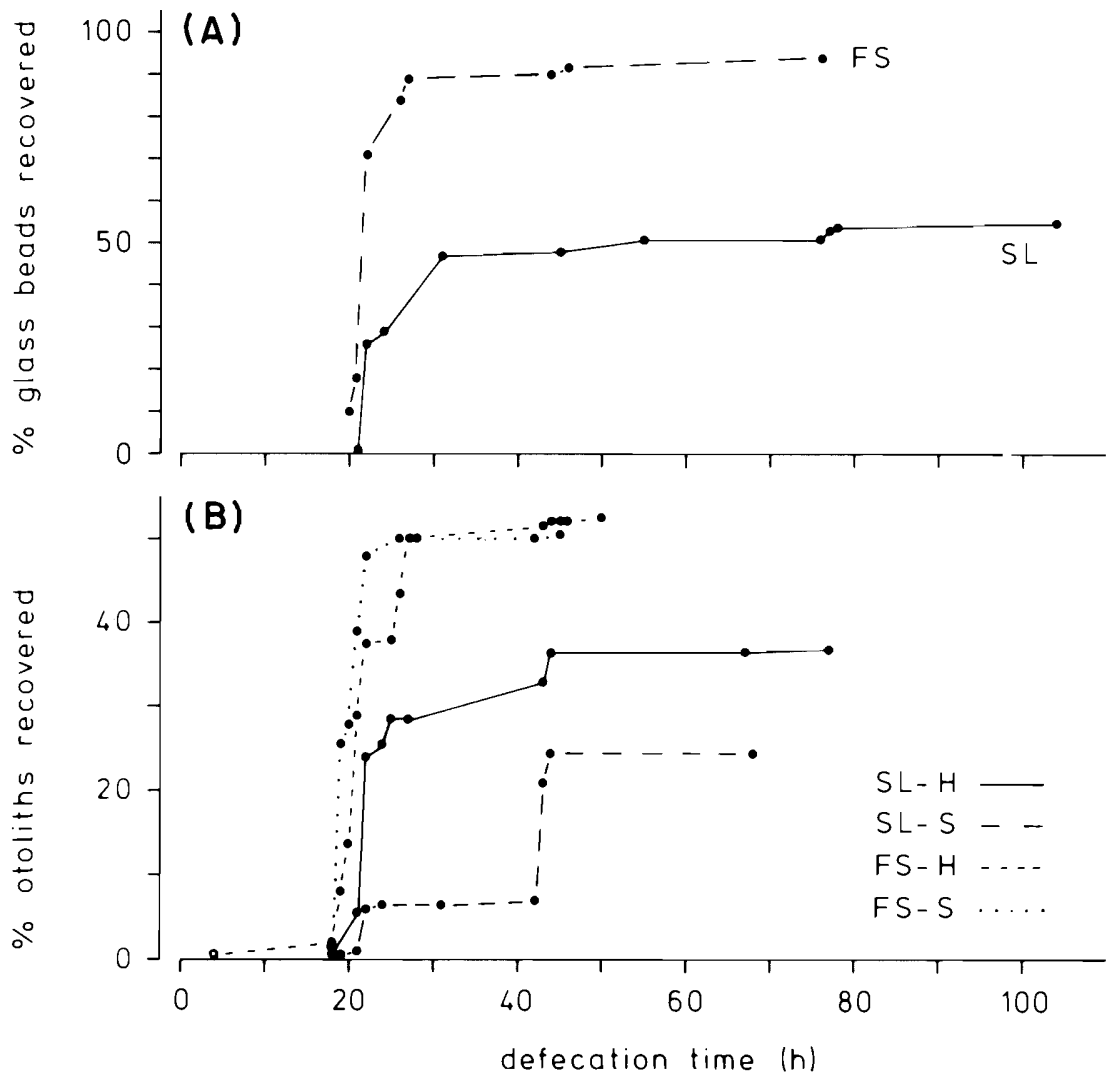

FIG. 1. Cumulative recovery of glass beads (A) and otoliths (B) from scats as a function of defecation time (in hours after experimental feeding). SL, sea lions; FS, fur seals; H, herring; S, sprat.

Half-times ranged between 17.5 and $44 \mathrm{~h}$ (median $21.9 \mathrm{~h}$ ). No difference in half-times was found between herring and sprat otoliths (Wilcoxon signed-ranks test: $T=-0.135, n=$ 14 , ns) or between sea lions and fur seals (Fig. 1; MannWhitney $U$-test, $n_{1}=16, n_{2}=17$, ns). The correlation between otolith length and half-times was insignificant $(r=$ $0.03, n=844$ ), i.e., passage half-times were independent of otolith size, and separation of otoliths according to size did not occur during passage through the intestinal tract.

The glass beads fed in the experimental feedings had halftimes similar to those of otoliths (Fig. 1), ranging from 20 to $31 \mathrm{~h}$ (median $22 \mathrm{~h}$ ). Again no difference was found between the seal species. In only two cases did a sea lion retain most of the glass beads beyond the end of the experiment; once the animal produced only two scats, and once it produced very small liquid stools.

Almost all glass beads given before the experimental feeding were eliminated within 25 h, i.e., before the onset of experimental scat collection. This observation implies that passage half-times were shorter for the same individuals when they were moving about and swimming in the pool before the experiment than when they were held in the boxes on dry land during the experiments.

\section{Reduction in otolith length by digestion}

Distribution of otolith length in scats was significantly different from that estimated by eqs. 1 and 4 in Table 2 for the fishes in the experimental meals (Mann-Whitney $U$-tests: $p<0.001$; see Fig. 2 for a comparison of the normalized distributions). The estimated length of herring otoliths in the meals was $4.05 \pm 0.25 \mathrm{~mm}(n=778)$, and of sprat otoliths, $1.96 \pm 0.07 \mathrm{~mm}(n=952)$. In the scats, herring otoliths aver- aged $17.4 \%$ and sprat otoliths $12.2 \%$ shorter than expected from fish size in the meals. The difference in the reduction in otolith size between fish species was not significant (MannWhitney $U$-test: $n_{1}=n_{2}=9$, ns). No difference was found in reduction in otolith length between the two seal species.

Estimating standard length of fish from otoliths recovered in scats using regression eqs. 2 and 5 in Table 2 resulted in an average underestimate of $16 \%$. Because of the cubic relationship between length and mass, fish mass estimated from otolith length in scats (using eqs. 3 and 6 in Table 2) underestimated actual fish mass by $36 \pm 7 \%(n=9)$ for herrings and $33 \pm 11 \%(n=9)$ for sprat.

\section{Proportion of otoliths recovered in scats}

The proportion of herring otoliths (herring/(herring + sprat); $\mathrm{H} /(\mathrm{H}+\mathrm{S}))$ in scats was compared with the known proportion of herring in the experimental meals. Even for a given experiment this proportion varied noticeably from scat to scat. Regressing all proportions of otoliths found in scats against proportions in the corresponding meals (Fig. 3A, Table 3) resulted in (mostly) significant relationships. Sometimes a seal appeared to be constipated, probably because of the close confinement during the experiment, and only a few otoliths were recovered. Excluding such experiments, in which less than $10 \%$ of the otoliths were recovered, a highly significant regression between diet composition and proportion of herring otoliths in scats was found (Fig. 3B, Table 3). To exclude these experiments seems justified since seals in the field are always vigorously exercising and the constipation occurring in a few experiments appeared to be caused by the artificial condition of confinement on dry land.

The difference between regressions for sea lions and fur 
$S L$

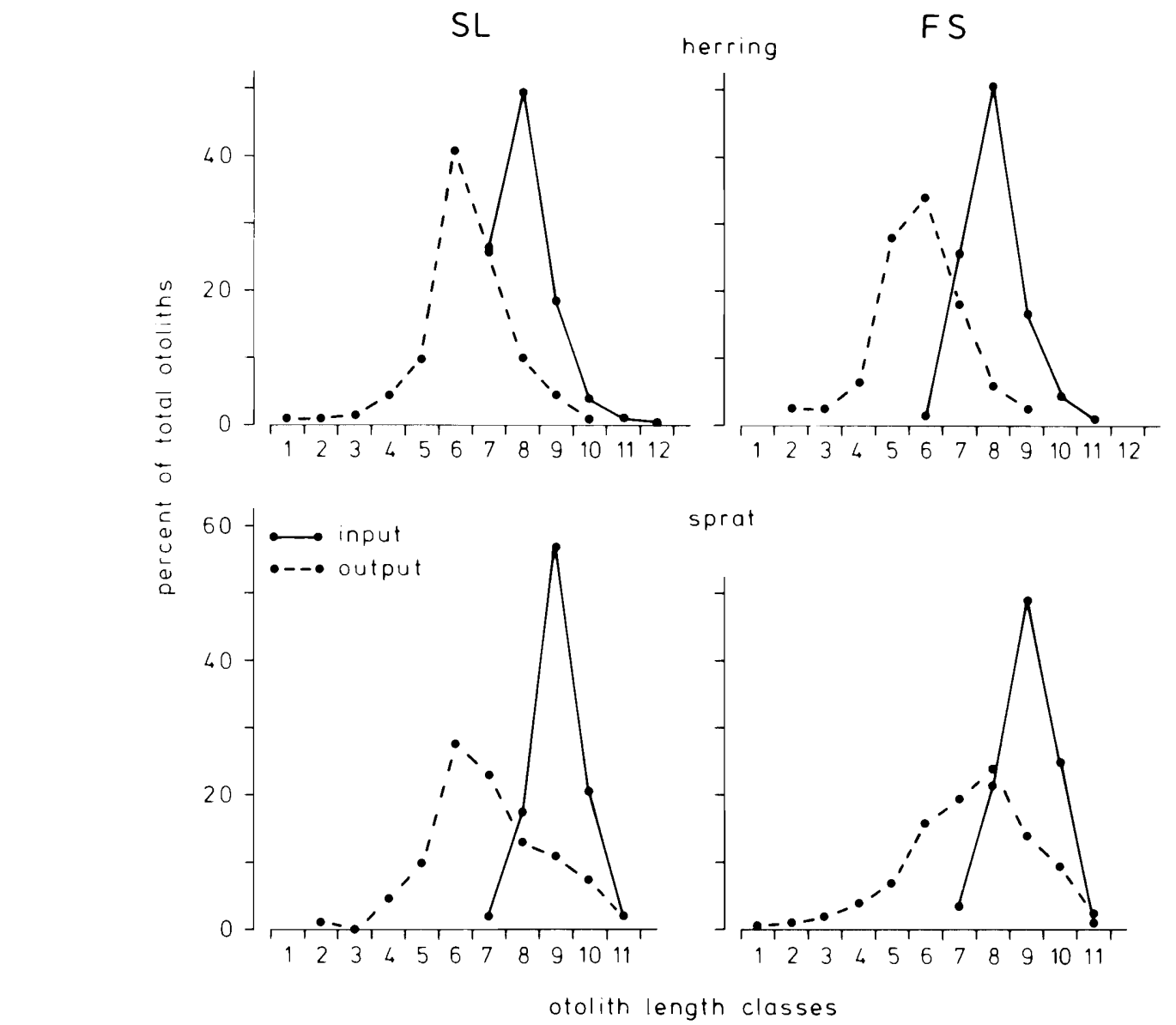

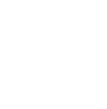

FIG. 2. Distribution of herring and sprat otolith length classes as percentage of total otolith number ingested at experimental feeding (input) and percentage of total otoliths recovered from scats (output). SL, sea lions; FS, fur seals. Otolith class width for herring is 0.3 mm (1.80$5.39 \mathrm{~mm} ; 12$ classes), and for sprat, $0.1 \mathrm{~mm}(1.10-2.19 \mathrm{~mm} ; 11$ classes $)$.

seals were never significant (analysis of covariance: slopes $p=0.56$, intercepts $p=0.66$ ). Since most of the regression slopes in Table 3 were close to 1 and intercepts were not far from 0 , numerical composition of the diet was usually estimated correctly from scats. A small underestimate of the smaller sprat otoliths still persisted $(8.8 \%$ from the regression means or $7.7 \pm 21.1 \%$ from experiment means; $n=16$ ).

\section{Discussion}

\section{Recovery of otoliths}

The low mean recovery rate of only $38.5 \%$ of all otoliths cannot be explained by retention of missing otoliths. Passage half-times were on the order of $22 \mathrm{~h}$ for both otoliths and glass beads. Our experiments thus covered usually about four halftimes, but hardly any otoliths or glass beads were defecated later than $30 \mathrm{~h}$ after the experimental feeding. Missing otoliths either must have been digested completely or were smaller than the smallest mesh size $(0.5 \mathrm{~mm})$ and therefore were not recovered. As mean glass bead recovery was only $74 \%$, i.e., $26 \%$ somehow got lost, we cannot exclude the possibility that $26 \%$ of the otoliths were also lost. Even so, about $35 \%$ of all ingested otoliths would have been destroyed by digestion (assuming 39\% recovered $+26 \%$ lost $+35 \%$ dissolved $=$ $100 \%$ ). However, the main loss of glass beads occurred in one experiment on sea lion No. 2 and in the second experiment with fur seal No. 6 when the animals were obviously not digesting normally.
Nearly complete recovery of otoliths from fish consumed has sometimes been tacitly assumed (Fitch and Brownell 1968; Treacy and Crawford 1981; Ainley et al. 1982) but our data as well as those from previous experiments do not support this assumption (Prime 1979; Hawes 1983; DaSilva and Neilson 1985; Murie and Lavigne 1986). Only Prime and Hammond (1987) reported $78 \%$ recovery in an experiment on grey seals (Halichoerus grypus). Otherwise, recovery varied from $4 \%$ for one common seal, Phoca vitulina (DaSilva and Neilson 1985), fed with herring, to $35 \%$ for one California sea lion (Hawes 1983) fed with three different fish species. In our own experiments recoveries varied from 1.25 to $87.3 \%$ in sea lions and from 3.8 to $80 \%$ in fur seals. The latter two values represent the results of two experiments on the same individual under identical conditions. Therefore, high variance in otolith recovery between experiments presently precludes any interpretation of differences in mean recovery rates.

The mechanisms responsible for total or partial recovery have been elucidated by Murie and Lavigne (1985). In the stomachs of grey seals killed at defined times after feeding they found that otoliths remaining in the fish skull case were undigested while others from the same meal, which had fallen out of the skull case, showed strong signs of digestion. They concluded that the probability of digestion of otoliths is highly variable depending on the species and size of fish, the position of a given fish within the stomach content, and the chance of the skull case being broken open. Taken together, the variance of otolith recovery in experiments, the knowledge about the 


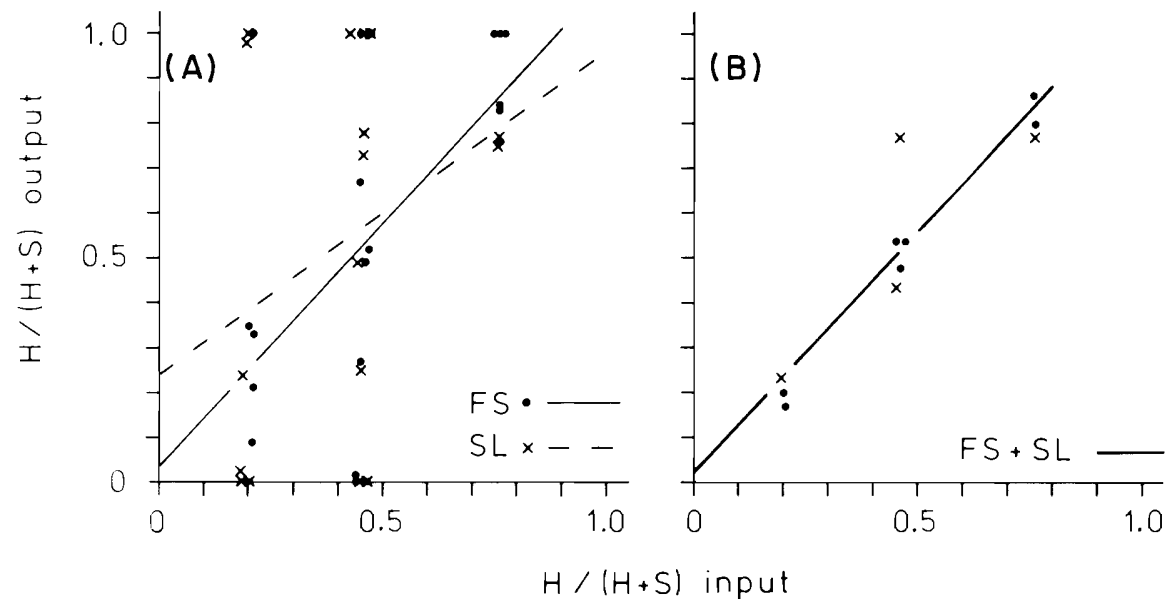

FIG. 3. Regression of the proportion of otolith types in scats $(Y)$ on the proportion of otolith types in the experimental meals $(X)$. Fig. 3A. All data from single scats with the regressions for sea lions and fur seals (eqs. 1 and 3 in Table 3 ). Slopes are significantly different from zero, but not from each other (analysis of covariance). Fig. 3B. Proportions for the sum of otoliths recovered from a given animal in a given experiment with $>10 \%$ recovery, for sea lions and fur seals together (regression: $Y=0.96 X+0.10 ; n=16, r=0.68, p=0.004$ ). SL, sea lions; FS, fur seals; H, herring; S, sprat.

TABLE 2. Regression equations with otolith length, fish standard length, and fish mass (from dissected fresh fish)

\begin{tabular}{lcc}
\hline \hline \multicolumn{1}{c}{ Equation } & $r$ & $n$ \\
\hline [1] $\mathrm{OL}=0.20(\mathrm{StL})-0.12$ & 0.87 & 41 \\
[2] $\mathrm{StL}=3.79(\mathrm{OL})+5.83$ & 0.87 & 41 \\
[3] $\ln M=2.57(\ln \mathrm{OL})+1.21$ & 0.84 & 41 \\
[4] $\mathrm{OL}=0.12(\mathrm{StL})-0.50$ & 0.89 & 41 \\
[5] $\mathrm{StL}=6.65(\mathrm{OL})+1.01$ & 0.89 & 41 \\
[6] $\ln M=3.31(\ln \mathrm{OL})+0.70$ & 0.91 & 34 \\
\hline
\end{tabular}

NoTE: OL, otolith length; StL, fish standard length $M$, fish mass. All regressions are significant at $p<0.001$

mechanism of otolith digestion, and the impossibility of collecting all fecal material from wild animals preclude reasonable estimates of absolute numbers of fish ingested by freeliving seals from scat analysis.

\section{Passage half-times}

Passage half-times in the present study were much higher than the initial defecation times (IDTs) measured by Helm (1984) for sea lions. The sea lions' IDTs were $4.2 \mathrm{~h}$ in Helm's study and our passage half-times were $22 \mathrm{~h}$ for sea lions and fur seals alike. This difference is partly one of definition: the earliest scat containing otoliths after experimental feeding was produced by a fur seal after $4 \mathrm{~h}$. Also, Helm's animals were apparently free to move in and out of a pool and often defecated upon entering the pool. Our animals had much less freedom of movement which apparently slowed digestion. During the confinement period we recovered hardly any of the glass beads given on the day before the experimental feeding, suggesting that the animals passed gut contents much faster when moving freely. The sea lions' digestive functioning might have been affected more strongly by the confinement than that of the fur seals since sea lions in captivity spent more time swimming. This characteristic could explain the very low otolith recovery from sea lion No. 2 and leads us to expect a shorter passage half-time under free-ranging conditions.

\section{Partial digestion of otoliths}

The bigger herring otoliths lost slightly more length through
TABLE 3. Regression equations for the proportion of herring otoliths in single scats $(Y)$ as a function of the proportion in the meals $(X)$

\begin{tabular}{lccrr}
\hline \multicolumn{1}{c}{ Data set } & Equations & $r$ & \multicolumn{1}{c}{$p$} & $n$ \\
\hline SL & [1] $Y=0.71 X+0.24$ & 0.31 & 0.225 & 17 \\
SL, $>10 \%$ & [2] $Y=1.38 X-0.14$ & 0.65 & 0.041 & 10 \\
FS & [3] $Y=1.09 X+0.03$ & 0.59 & 0.005 & 21 \\
FS, $>10 \%$ & [4] $Y=1.05 X-0.10$ & 0.64 & 0.003 & 19 \\
SL + FS & [5] $Y=0.93 X+0.13$ & 0.47 & 0.003 & 38 \\
SL + FS, $>10 \%$ & [6] $Y=1.16 X+0.02$ & 0.65 & $<0.001$ & 29
\end{tabular}

NoTE: SL, sea lion; FS, fur seal; > $10 \%$, data of experiments in which more than $10 \%$ of the otoliths in the meals were recovered in the scats. Data of experiments in which the diet consisted of herring only were not included.

digestion than sprat otoliths although the difference proved significant only if the data from sea lion No. 2 were omitted. Even more substantial differences may occur in the digestion of otoliths of less closely related fish species (herring and sprat are both members of Clupeidae) or of species with larger differences in otolith size and structure. Fish length and mass estimated from otoliths recovered in our experiments would have been underestimated by 15 and $35 \%$, respectively. These are maximal underestimates since passage half-times in wild, freely moving animals would presumably be shorter, reducing the time during which otoliths would be exposed to digestive fluids. Nevetheless, published results on seal prey sizes and total mass consumed (North et al. 1983; Antonelis and Perez 1984; Antonelis et al. 1984; George-Nascimento et al. 1985) are likely to be underestimates. To assess the errors involved, controlled feeding experiments for every prey item and seal species would be necessary. Even so, no easy correction for changes in length during digestion seems possible since the distribution of otolith length in the scats after digestion was significantly greater than in the fed diet (see Fig. 2).

\section{Estimating the proportion of prey species in the diet}

The ratios of herring to sprat otoliths in scats correspond closely to those in the diet but the variance is high. Large samples of scats are therefore necessary to obtain a reasonable picture of the numerical composition of the diet of wild populations. Some authors have suggested that the number of smaller otoliths may be underestimated (Fitch and Brownell 
1968; Prime 1979; DaSilva and Neilson 1985). Our results support this hypothesis: $8 \%$ fewer of the smaller sprat otoliths were recovered relative to the herring otoliths. Hawes (1983), feeding three different fish species sequentially, also found that recovery of anchovy (Engraulis mordax) otoliths was lower than that of the bigger jack mackerel (Trachurus symmetricus) otoliths. Nevertheless, smaller otoliths are not passed more quickly than larger ones. Consequently, the proportion of fish species in the diet (by number, not biomass) will be quite accurately assessed even for animals returning from a long trip at sea, provided that large numbers of scats are analysed and that on their return trip the seals do not fish for food that is different from their diet while far out at sea.

It seems, therefore, that reliable estimation of diet composition in terms of biomass or energy ingested is not possible from scat analysis, while the numerical proportion of different prey species may be estimated correctly from large samples of scats.

\section{Acknowledgements}

We wish to thank the Munich Zoo "Hellabrunn" and its director, Dr. H. Wiesner, for the opportunity to work with the seals and use the facilities. Assistance and help with handling the seals by $\mathbf{H}$. Nelz was greatly appreciated. B. Knauer kindly drew the graphs. We also wish to thank our colleagues from Seewiesen, those from the animal behavior group at the University of Konstanz, Federal Republic of Germany, and D. Lavigne for constructive criticism. This study was supported by the Max-Planck Institut für Verhaltensphysiologie, Abteilung Wickler.

Ainley, D. G., Huber, H. R., and Bailey, K. M. 1982. Population fluctuations of California sea lions and the Pacific whiting fishery off central California. Fish. Bull. 80: 253-258.

Antonelis, G. A., and Perez, M. A. 1984. Estimated annual food consumption by northern fur seals in the California current. Calif. Coop. Oceanic Fish. Invest. Rep. 25: 135-145.

Antonelis, G. A., Fiscus, C. A., and Delong, R. L. 1984. Spring and summer prey of California sea lions, Zalophus californianus, at San Miguel Island, California, 1978-1979. Fish. Bull. 82: 67 76.

DaSilva, J., and Neilson, J. D. 1985. Limitations of using otoliths recovered in scats to estimate prey consumption in seals. Can. J. Fish. Aquat. Sci. 42: 1439-1442.

Degens, E. T., Deuser, W. G., and Haedrich, R. L. 1969. Molecular structure and composition of fish otoliths. Mar. Biol. (Berlin), 2: $105-113$.

Fitch, J. E., and Brownell, R. L., JR. 1968. Fish otoliths in cetacean stomachs and their importance in interpreting feeding habits. J. Fish. Res. Board Can. 25: 2561-2574.

George-Nascimento, M., Bustamante, R., and Oyarzun, C. 1985. Feeding ecology of the South American sea lion Otaria flavescens: food contents and food selectivity. Mar. Ecol. Prog. Ser. 21: $135-143$.

HAWES, S. D. 1983. An evaluation of California sea lion scat samples as indicators of prey importance. M.Sc. thesis, San Francisco State University, San Francisco.

Helm, R. C. 1984. Rate of digestion in three species of pinnipeds. Can. J. Zool. 62: $1751-1756$.

Murie, D. J., and Lavigne, D. M. 1985. Digestion and retention of Atlantic herring otoliths in the stomachs of grey seals. In Marine mammals and fisheries. Edited by J. R. Beddington, R. J. H. Beverton, and D. M. Lavigne. George Allen \& Unwin, London. pp. 293-299.

North, A. W., Croxall, J. P., and Doidge, D. W. 1983. Fish prey of the Antarctic fur seal Arctocephalus gazella at South Georgia. Br. Antarct. Surv. Bull. 61: 27-37.

Prime, J. H. 1979. Observations on the digestion of some gadoid fish otoliths by a young common seal. Mar. Mamm. Comm., Int. Counc. Explor. Sea, Rep. No. CM 1979/N: 14.

Prime, J. H., and HAMmond, P. S. 1987. Quantitative assessment of grey seal diet from fecal analysis. In Approaches to marine mammal energetics. Edited by A. C. Huntley, D. P. Costa, G. A. J. Worthy, and M. A. Castellini. Society for Marine Mammalogy, Spec. Publ. No. 1. Allen Press, Lawrence, KS. pp. 165-181.

Treacy, S. D., and CraWford, T. W. 1981. Retrieval of otoliths and statoliths from gastrointestinal contents and scats of marine mammals. J. Wildl. Manage. 45: 990-993. 